\title{
Evaluation of the functional results and complications of trans-septal suture technique in septoplasty
}

\begin{abstract}
Objectives: To evaluate functional results and complications of trans-septal suturing compared with nasal packing following septoplasty.

Background: Debate still persists about using trans-septal suturing as a safe and useful alternative to nasal packing in septoplasty.

Patients and methods: This prospective study included 64 patients who presented to ENT outpatient clinics of Menoufia University and Kafr El-Sheikh General Hospitals complaining of persistent nasal obstruction due to septal deviation and underwent septoplasty under general anesthesia from October 2016 till September 2017. Patients were randomly divided into 2 groups; trans-septal suturing group (A) and nasal packing group (B), and were assessed for operative time, post-operative hospital stay, complications, and functional outcomes using Nasal Obstruction Symptom Evaluation (NOSE) scale.
\end{abstract}

Results: Operative times were longer in group A $(4.094 \pm 1.027)$ than B $(1.438 \pm 0.416)$. Post-operative bleeding was more frequent in group A (21.87\%) than B (6.25\%). Postoperative nasal obstruction $(100 \%)$, pain $(100 \%)$, headache $(84.38 \%)$, epiphora $(37.5 \%)$, swallowing discomfort (31.25\%), sleep disturbances $(81.25 \%)$, pack removal hazards as pain $(87.5 \%)$, syncope (25\%) and bleeding $(25 \%)$, local infection (25\%), granulation tissue formation $(34.37 \%)$, synechia $(34.37 \%)$ and post-operative hospital stay $(\mathrm{P}<0.001)$ were prevailing in group B. Septal hematoma, abscess, and perforation were non-significant in both groups. NOSE Scores in both groups pre- and post-operatively showed high significant improvements in all parameters $(\mathrm{P}<0.001)$ in group $\mathrm{A}$.

Conclusion: Trans-septal suturing is a safe procedure and useful alternative to nasal packing in septoplasty with minor increase in operative time and post-operative bleeding which is easy to control.

Keywords: nasal packing, septoplasty, trans-septal suturing
Volume 10 Issue I - 2018

\author{
Abd El Hay Rashad El Assi, I Yaser Abd El \\ Wahab Khalil, I Ibrahim Ahmed Abd El \\ Shafy, I Hosam Adel Hussein, I Salah Yousuf \\ Abd El Aziz2 \\ 'ENT Department, Menoufia University, Egypt \\ ${ }^{2}$ ENT Department, KFS General Hospital, Egypt
}

Correspondence: Ibrahim Ahmed Abd El-Shafy, ENT Department, Menoufia University, Shebin El-Kom, Menoufia, Egypt, Tel +2 010028I26I2, Email lbrahim_ent@yahoo.com

Received: January 24, 2018| Published: February 05, 2018

\section{Introduction}

Septoplasty is the main surgical procedure to overcome nasal obstruction caused by septal deviation ${ }^{1}$ and is one of the most common operations in otorhinolaryngology. ${ }^{2}$ It has a long history with multiple variations, but the core principles have remained unchanged for decades. ${ }^{3}$ But this surgery may be associated with numerous complications such as post-operative nasal bleeding, septal hematoma, septal perforation, and nasal adhesions. ${ }^{4}$ To minimize the rate of these complications, otolaryngologists, mostly pack both nasal cavities with different types of nasal packing ${ }^{5}$ which is thought to stabilize the remaining cartilaginous septum and minimize persistence or recurrence of septal deviation also. Post-operative pain, discomfort, worsening of breathing, sleep disorders, mucosal injury, and post-operative infections are complications associated with nasal packing. The unpleasant part of this procedure is the discomfort and pain during pack removal. ${ }^{6}$

Therefore, the use of nasal packing is associated with several risks that should question the routine application of this procedure, especially given the lack of firm evidence to support its efficacy. ${ }^{7}$ Studies that compare septoplasty with and without nasal packing are available ${ }^{8}$ and there have been few studies suggesting that nasal packing should not be used because of the discomfort at the time of removal. ${ }^{9}$ Alternately, pack-free septoplasty performed with trans-septal sutures has been suggested as it reduces morbidity. ${ }^{10}$ Most of these previous studies compared the complications of these methods and there are limited data available regarding the comparison of outcomes after nasal packing or trans-septal suturing. ${ }^{11}$

The aim of this study was to evaluate functional results and complications of trans-septal suturing compared with nasal packing following septoplasty.

\section{Patients and methods}

This prospective study included 64 patients selected from ENT outpatient clinics of Menoufia University Hospital and Kafr ElSheikh General Hospital from October 2016 till September 2017. The study was approved from the institutional ethical committee of Menoufia University Hospital's Review Board and written consents were taken from all patients before surgical intervention. This study included patients complaining of persistent nasal obstruction due to septal deviation inspite of management of nasal infections and trials of medical treatment. Patients with rhinosinusitis, vasomotor rhinitis, other causes of nasal obstruction, nasal polyps, hypertrophied inferior turbinates, external nasal deformity, previous nasal surgery, ages under 18 years and those with debilitating disease or were considered unfit for surgery were excluded from the study. Patients were subjected to detailed history taking, complete clinical ENT examination, CT 
scan (Multidetector CT Scanner, GE Healthcare, USA, Light Speed Ultra 8 Slice, Thin cuts $2 \mathrm{~mm}$ ) of the nose and paranasal sinuses, and routine preoperative assessment and laboratory investigations. Nasal obstruction was scored with NOSE Scale 1week preoperatively. NOSE scale is a disease-specific scale prepared to evaluate nasal obstruction by the American Academy of Otolaryngology-Head and Neck Surgery Foundation (AAO-HNS Foundation). It is a valid, reliable, and responsive instrument that is brief and easy to complete and has potential use for outcomes studies in adults with nasal obstruction (Table 1)..$^{12}$

Septoplasty was performed under general anaesthesia. After subperichondrial injection of a solution containing 2\% Lidocaine with 1/100000 Epinephrine, a hemitransfixation incision was done, then the mucoperichondrium and mucoperiosteum was elevated on one side of the septum then contralateral mucoperichondrium and mucoperiosteum were elevated. While deviations of the cartilage were corrected with excisions, scoring or sutures preserving L-strut support, deviations of the bone were corrected by excisions. The surgical incisions were closed by $4 / 0$ vicryl and by the end of surgery, patients were randomly selected to have either trans-septal sutures (group A) or nasal packs (group B). In group A (32 patients), 2-6 separate trans-septal sutures were done horizontally, vertically or obliquely according to the elevated mucosal flaps of the septum using 4/0 Vicryl (4/0, 18" Vicryl Rapid Absorbable Coated Suture with Precision Point Reverse Cutting P-3, 3/8 circle Needle, Ethicon, USA) and the least number of sutures enough to stabilize the septum was applied. In group B (32 patients), the nasal cavities were blocked with Merocel (Merocel standard 8-cm nasal dressing without airway, Medtronic Xomed Inc., FL, USA) nasal packs which were inserted along the floor of both nasal cavities and then irrigated with saline.

The operative times for trans-septal sutures and for packing were recorded, post-operative care was done, nasal packs were removed 48hours post-operatively and follow up was done.

\section{Outcomes}

Both groups were assessed for operative times for sutures and packing, post-operative hospital stay, post-operative complications (Post-operative bleeding, nasal obstruction, pain, headache epiphora, discomfort in swallowing and sleep disturbances, nasal pack removal hazards as pain, syncope and bleeding, septal hematoma, septal abscess, septal perforation, local infection, granulation tissue formation and synechia), and the functional outcomes were evaluated using NOSE scale.

\section{Statistical analysis}

Statistical presentation and analysis of this study was conducted with Statistical Package for the Social Sciences (SPSS V 17), IBM, Armonk, NY, United States of America. Mean value and Standard Deviation (SD) were used for quantitative data, and Frequency and percentage for qualitative data. Unpaired Student T-test was used to compare between two groups in quantitative data. Paired Student T-test was used to compare between related samples. $X^{2}$ (Chi square test) was used to compare between two independent qualitative variables normally distributed. All these tests were used as tests of significance at $\mathrm{P}$ value $<0.05$.

\section{Results}

This study included 64 patients (23 males and 41 females) (18 - 50years old). In group A there were 13 males $(40.63 \%)$ and 19 females $(59.38 \%)$, and in group B there were 10 males $(31.25 \%)$ and 22 females $(68.75 \%)$. The mean age of group A was $25.813 \pm$ 7.532 years (Range: 18 - 50years) and of group B was $26.813 \pm 7.027$ years (Range: 18 -42years). So, the preoperative characteristics of both groups showed no significant statistical difference between them as regards age and sex.

The mean operative time for trans-septal sutures in group A was $4.094 \pm 1.027$ minutes (Range: 2.5 - 6minutes) and for nasal packing in group B was $1.438 \pm 0.416$ minutes (Range: $1-2.5$ minutes). It was longer and highly significant in group $\mathrm{A}(\mathrm{P}<0.001)$.

As regards post-operative nasal bleeding, pain and hospital stay; In group A, 7 patients $(21.87 \%)$ had bleeding, only 2 of them $(6.25 \%)$ needed nasal packing to control their bleeding in the $1^{\text {st }}$ postoperative day and in group B, only 2 patients $(6.25 \%)$ had minor trickling of post nasal bleeding which stopped with medical treatment and observation. So, bleeding was more frequent in group A, but it showed no significant statistical difference between both groups ( $\mathrm{P}$ 0.154) (Table 2).

Post-operative pain was recorded using the Visual Analogue Scale (VAS) for 48 hours post-operatively and it showed high significant statistical difference in group $\mathrm{B}(\mathrm{P}<0.001)$ (Table 2).

The post-operative hospital stay in group A was 24 hours for 30 patients $(93.75 \%)$ while for 2 patients $(6.25 \%)$ it was 72 hours as they had major bleeding which required nasal packing to stop. All patients $(100 \%)$ of group B had nasal packing, so they had to stay for at least 48 hours. 27 patients $(84.37 \%)$ of group B were discharged after removal of their packs 48 hours post-operatively and 5 patients $(15.63 \%)$ had to stay for another 24hours under observation as they had minor bleeding. So, the post-operative hospital stay was longer and showed high significant statistical difference in group $\mathrm{B}(\mathrm{P}<0.001)$ (Table 2).

Post-operative nasal obstruction was present in all patients (100\%) of group B and in the only 2 patients $(6.25 \%)$ of group A, who needed packing in the $1^{\text {st }}$ post-operative day. So, post-operative nasal obstruction, sleep disturbances and headache were more frequent in group $\mathrm{B}$ and showed high significant statistical difference $(\mathrm{P}<0.001)$ (Table 3).

Synechia was more common in group B and showed significant statistical difference (P 0.007). The post-operative complications of both groups showed no significant statistical difference between them as regards septal hematoma, septal abscess, granulation tissue formation and local infection with higher incidence of local infection $(25 \%)$ and granulation tissue formation $(34.37 \%)$ in group B. Neither septal perforation nor nasal deformity had occurred in both groups (Table 3).

Pack removal was accompanied by many hazards such as pain, syncope, and bleeding. In group A, 2 patients $(6.25 \%)$ had postoperative bleeding which was controlled using nasal packing, on removal of their packs, 1 patient $(3.12 \%)$ had pain and the other one $(3.12 \%)$ had minor bleeding. In group B, 28 patients $(87.5 \%)$ had pain, 8 patients $(25 \%)$ were syncoped and 8 patients $(25 \%)$ had minor bleeding during pack removal. The worst was that 1 of our patients $(3.12 \%)$ had psychic trauma and insisted on removal of her nasal packs under general anaesthesia. So, syncope and bleeding during pack removal were significant and pain during pack removal was highly significant $(\mathrm{P}<0.001)$ in group $\mathrm{B}$ (Table 4$)$.

NOSE scale evaluation of nasal obstruction was scored in this study 1week preoperatively and 2 months post-operatively. Preoperatively, there was no significant statistical difference between NOSE scores 
of both groups. Post-operatively, there was high significant statistical improvement $(\mathrm{P}<0.001)$ in nasal obstruction using NOSE score in patients of group A compared to group B. In both groups, there was high significant statistical improvement in nasal obstruction

Table I Nasal Obstruction Symptom Evaluation (NOSE) scale [12] according to NOSE score pre- and post-operatively. So, by comparing the pre- and post-operative NOSE scores, there were high significant statistical improvements in all parameters with better results in group A $(\mathrm{P}<0.001)$ (Table $5 \&$ Figure 1$)$.

\begin{tabular}{|c|c|c|c|c|c|}
\hline & $\begin{array}{l}\text { Not a } \\
\text { Problem }\end{array}$ & Very Mild & Moderate & $\begin{array}{l}\text { Fairly Bad } \\
\text { Problem }\end{array}$ & Severe \\
\hline & & Problem & Problem & & Problem \\
\hline Nasal congestion or stuffiness & 0 & 1 & 2 & 3 & 4 \\
\hline Nasal blockage or obstruction & 0 & I & 2 & 3 & 4 \\
\hline Trouble breathing through my nose & 0 & 1 & 2 & 3 & 4 \\
\hline Trouble sleeping & 0 & I & 2 & 3 & 4 \\
\hline Unable to get enough air through my nose during exercise or exertion & 0 & 1 & 2 & 3 & 4 \\
\hline
\end{tabular}

Table 2 Comparison between post-operative bleeding, pain and hospital stay in both groups

\begin{tabular}{|c|c|c|c|c|c|c|c|c|c|}
\hline & & \multicolumn{6}{|c|}{ Groups } & \multicolumn{2}{|c|}{ Chi-Square } \\
\hline & & \multicolumn{2}{|c|}{ Group A $(n=32)$} & \multicolumn{2}{|c|}{ Group B $(n=32)$} & \multicolumn{2}{|c|}{ Total } & \multirow[b]{2}{*}{$\mathbf{X 2}$} & \multirow[b]{2}{*}{ P-Value } \\
\hline & & $\mathbf{N}$ & $\%$ & $\mathbf{N}$ & $\%$ & $\mathbf{N}$ & $\%$ & & \\
\hline \multirow[t]{3}{*}{ Bleeding } & No & 25 & 78.12 & 30 & 93.75 & 55 & 85.93 & 3.74 & 0.154 \\
\hline & Minor & 5 & 15.62 & 2 & 6.25 & 7 & 10.93 & & \\
\hline & Major & 2 & 6.25 & 0 & 0 & 2 & 3.12 & & \\
\hline \multirow[t]{4}{*}{ Pain } & No & 25 & 78.12 & 0 & 0 & 25 & 39.06 & 47.667 & $<0.00 I^{*}$ \\
\hline & Mild & 5 & 15.62 & 4 & 12.5 & 9 & 14.06 & & \\
\hline & Moderate & I & 3.12 & 17 & 53.12 & 18 & 28.12 & & \\
\hline & Severe & I & 3.12 & II & 34.37 & 12 & 18.75 & & \\
\hline \multirow[t]{3}{*}{ Hospital stay } & 24 hs. & 30 & 93.75 & 0 & 0 & 30 & 46.88 & 58.286 & $<0.001 *$ \\
\hline & 48 hs. & 0 & 0 & 27 & 84.37 & 27 & 42.19 & & \\
\hline & 72 hs. & 2 & 6.25 & 5 & 15.63 & 7 & 10.94 & & \\
\hline
\end{tabular}

*P value: Significant; hs: hour

Table 3 Comparison between incidence of post-operative nasal obstruction, epiphora, swallowing discomfort, sleep disorders, headache, septal hematoma, infection, granulation tissue formation and synechia in both groups

\begin{tabular}{|c|c|c|c|c|c|c|c|c|}
\hline & \multicolumn{6}{|c|}{ Groups } & \multicolumn{2}{|c|}{ Chi-Square } \\
\hline & \multicolumn{2}{|c|}{ Group A (n=32) } & \multicolumn{2}{|c|}{$\begin{array}{l}\text { Group B } \\
(n=32)\end{array}$} & \multicolumn{2}{|l|}{ Total } & \multirow[b]{2}{*}{$\times 2$} & \multirow[b]{2}{*}{ P-value } \\
\hline & $\mathbf{N}$ & $\%$ & $\mathbf{N}$ & $\%$ & $\mathbf{N}$ & $\%$ & & \\
\hline Nasal obstruction & 2 & 6.25 & 32 & 100 & 34 & 53.13 & 52.769 & $<0.001 *$ \\
\hline Epiphora & 2 & 6.25 & 12 & 37.5 & 14 & 21.88 & 9.143 & $0.002 *$ \\
\hline Swallowing discomfort & 0 & 0 & 10 & 31.25 & 10 & 15.63 & 11.582 & $0.001 *$ \\
\hline Sleep disorders & 2 & 6.25 & 26 & 81.25 & 28 & 43.75 & 36.571 & $<0.001 *$ \\
\hline Headache & 4 & 12.5 & 27 & 84.38 & 31 & 48.44 & 30.28 & $<0.001 *$ \\
\hline Septal hematoma & 1 & 3.12 & 1 & 3.12 & 2 & 3.12 & 0 & 1 \\
\hline Infection & 3 & 9.37 & 8 & 25 & II & 17.19 & 2.744 & 0.098 \\
\hline Granulation tissue formation & 5 & 15.62 & 11 & 34.37 & 16 & 25 & 3 & 0.083 \\
\hline Synechia & 5 & 15.62 & 15 & 46.87 & 20 & 31.25 & 7.273 & $0.007 *$ \\
\hline
\end{tabular}

*P value: Significant

Table 4 Comparison between incidence of pain, syncope and bleeding in both groups during pack removal

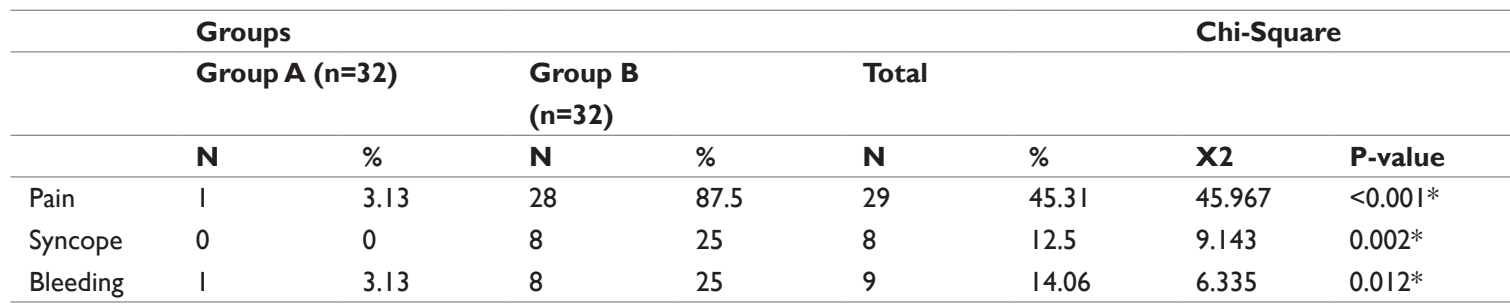

*P value: Significant

Citation: El Assi AEHR, KhalilYAEW, El Shafy IAA, et al. Evaluation of the functional results and complications of trans-septal suture technique in septoplasty.J Otolaryngol ENT Res. 2018;10(I):29-34. DOI: 10.15406/joentr.2018.10.00306 
Table 5 Comparison of NOSE scores pre- and post-operatively between both groups

\begin{tabular}{|c|c|c|c|c|c|}
\hline \multirow[t]{2}{*}{ Nose } & & \multicolumn{2}{|l|}{ Groups } & \multicolumn{2}{|l|}{ T-Test } \\
\hline & & Group A & Group B & $\mathbf{T}$ & P-Value \\
\hline \multirow[t]{2}{*}{ Pre } & Range & I5-Dec & I5-Dec & 1.506 & 0.137 \\
\hline & Mean \pm SD & $13.875 \pm 1.008$ & $13.500 \pm 0.984$ & & \\
\hline \multirow[t]{2}{*}{ Post } & Range & 6-Mar & 7-Apr & -6.338 & $<0.001 *$ \\
\hline & Mean \pm SD & $4.031 \pm 0.897$ & $5.406 \pm 0.837$ & & \\
\hline Differences & Mean \pm SD & $9.844 \pm 1.221$ & $8.094 \pm 0.963$ & & \\
\hline Paired Test & $\mathrm{P}$-value & $<0.001 *$ & $<0.001 *$ & & \\
\hline
\end{tabular}

*P value: Significant

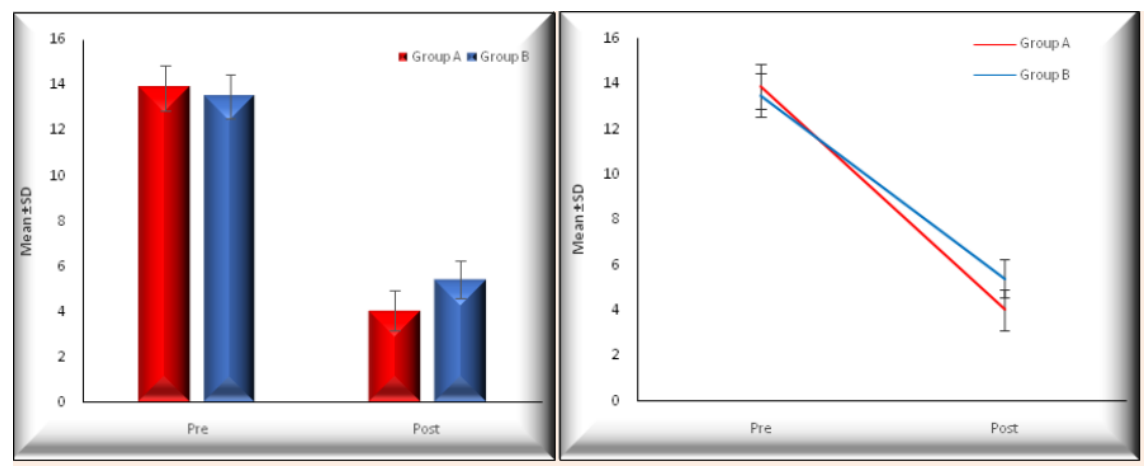

Figure I Two diagrams showing comparison of NOSE scores pre- and postoperatively between both groups.

\section{Discussion}

Nasal packing has been used in septoplasty for many decades to prevent bleeding, hematoma, perforation, and to stabilize the cartilage and bony skeleton. But this produced some quality of life problems for patients. Major problem was pain during nasal packing and at time of its removal. Intra nasal packing caused mucosal injury and septal perforation. ${ }^{6}$ Serious infections, aspiration and cardiologic complications had also occurred. ${ }^{13}$ Considering such complications, several studies have been conducted to evaluate the usefulness of nasal packing. Most of these studies showed that septoplasty can be safely performed without post-operative nasal packing and some complications could have been reduced by non-intranasal pack technique. ${ }^{14}$

In this study, to be accurate and specific and to decrease bias in operative time related to our target of study, we calculated the operative times only for trans-septal sutures and for nasal packing and not the whole time of septoplasty operation. The mean operative time for trans-septal suture group was longer longer and highly significant than that for packing group.

Post-operative bleeding was classified as either minor bleeding where treatment with $0.1 \%$ adrenaline-soaked cotton swabs for 2-5minutes and/or local decongestant nasal drops were/was sufficient to stop, or major bleeding, where the application of nasal packs was necessary to control. Post-operative bleeding was more frequent in patients of trans-septal sutures. In our trans-septal suture group, $21.8 \%$ of patients had bleeding; only $6.25 \%$ of them needed nasal packing at the $1^{\text {st }}$ post-operative day. In our packing group only $6.25 \%$ of patients had minor trickling of post nasal bleeding which stopped with medical treatment and observation. While in the study of Bernardo et al., ${ }^{15} 30.6 \%$ of patients of the trans-septal suture group had post-operative bleeding, only $2.7 \%$ of them needed nasal packing to control bleeding, and in the nasal packing group $10.8 \%$ of patients had post-operative bleeding.
In this study, only $6.25 \%$ of patients of trans-septal suture group complained of bilateral nasal obstruction in early post-operative days and this was due to insertion of nasal packs to control their bleeding whereas all patients $(100 \%)$ of nasal packing group complained of bilateral nasal obstruction due to nasal packing immediately postoperative and these results were consistent with the study of Ghimire et al. ${ }^{16}$ where $100 \%$ of patients of nasal packing group complained of bilateral nasal obstruction and $9.52 \%$ of patients of trans-septal suture group complained of bilateral nasal obstruction. Nasal obstruction can lead to increased bronchomotor tone leading to increased pulmonary and airway resistance and then to hypoxaemia. ${ }^{17}$

Nasal packing can also cause or worsen sleep-disordered breathing. ${ }^{18}$ In this study, only $6.25 \%$ of patients in trans-septal suture group had sleep disordered breathing as they had major postoperative bleeding which necessitated use of nasal packing, while in nasal packing group, $81.25 \%$ of patients had sleep disorders. These results were consistent with those found in the study of Awan and Iqbal, ${ }^{19}$ where $81.8 \%$ of patients in the packing group had sleep disturbance compared with $15.9 \%$ of patients in the no-packing group. Also epiphora and discomfort in swallowing were consistent with the above mentioned study. ${ }^{19}$

As regards pain in this study, all patients were asked to define their pain using Visual Analogue Scale (VAS) and nasal packing was found to be significantly more painful than trans-septal sutures. This was also demonstrated in the study of Cukurov et al., ${ }^{11}$ where post-operative pain was also evaluated based on VAS and showed that patients submitted to nasal packing had more pain than those submitted to sutures only.

In this study, post-operative headache was more frequent and highly significant in $84.38 \%$ of patients of nasal packing group compared to $12.50 \%$ of patients of trans-septal suture group. The study of Awan \& Iqbal ${ }^{19}$ showed that headache was present in $90.9 \%$ of patients with nasal packing compared with $20.5 \%$ of patients without nasal packing. 
Removal of packing proved to be the most painful event in the post-operative period. ${ }^{20}$ In this study, only $6.25 \%$ of patients of transseptal suture group had post-operative bleeding which was controlled using nasal packing and on removal of their packs, $3.12 \%$ of them complained pain and discomfort and the other $3.12 \%$ had minor bleeding. In nasal packing group, $87.5 \%$ of patients complained pain and discomfort, $25 \%$ of them had syncope and $25 \%$ had minor bleeding. We found that nasal packing was very distressing to the degree that one of our patients complained severe post-operative pain and insisted on removal of her nasal packing only under general anesthesia. Bernardo et al., ${ }^{15}$ described moderate to severe pain upon nasal pack removal in $75.7 \%$ of patients and Weber et al., ${ }^{21}$ described discomfort and vagal stimulation upon pack removal in many patients.

In this study, the post-operative hospital stay was longer in nasal packing group as the intranasal packs were removed 48 hours postoperatively and patients were kept in hospital during this period. These results were consistent with the study of Ghimire et al. ${ }^{16}$ where the mean hospital stay was longer in nasal packing group (2.8days) than in trans-septal suture group (1.2days). In our trans-septal suture group, $6.25 \%$ of patients required intranasal packs for epistaxis in the $1^{\text {st }}$ post-operative day and their packs were removed after 48 hours and these results was near those of Basha et al., ${ }^{22}$ where $3.2 \%$ of patients required post-operative nasal packing.

In this study, Septal hematoma occurred equally in both groups where it occurred in $3.12 \%$ of patients of each group and local infection occurred in $9.37 \%$ of patients of trans-septal suture group and in $25 \%$ of patients of nasal packing group but none of them had septal abscess, while in the study of Bernardo et al., ${ }^{15}$ no patient had septal hematoma, adhesions or local infection.

In this study, $15.62 \%$ of patients of trans-septal suture group had granulation tissue formation and $15.62 \%$ of patients had synechia, and in nasal packing group, $34.37 \%$ of patients had granulation tissue formation and $46.87 \%$ of patients had synechia, and in both groups, neither septal perforation nor nasal deformity had occurred. In the study of Ghimire et al., ${ }^{16}$ post-operative complications like synechia development, septal perforation and saddle nose deformity were more common in nasal packing group. These may be due to the mucosal injury and pressure necrosis of nasal septum associated with intranasal packing. ${ }^{16}$

Nasal obstruction was the main complaint presented by patients of this study and its improvement was considered the main indicator of the functional results and satisfaction of the patient. NOSE scale evaluation of nasal obstruction was scored 1 week preoperatively and 2 months post-operatively; Preoperatively, there were no significant differences between NOSE scores of patients of both groups, while post-operatively, both groups showed high significant improvements in nasal obstruction, and there were high significant improvements in nasal obstruction in patients of trans-septal suture group compared to nasal packing group. So, in comparing NOSE scores 1week preoperatively and 2 months post-operatively in both groups, there were improvements in nasal obstruction in all parameters with better results in trans-septal suture group. In the study of Bernardo et al., ${ }^{15}$ septoplasty improved nasal breathing and quality of life for all patients when assessed 3months after surgery, with no differences between the two groups. So, they could therefore conclude that nasal packing did not guarantee better surgical outcomes. Quality of life improvements measured through NOSE questionnaire of patients submitted to septoplasty had also been proven by Bezerra et al., ${ }^{23}$

Therefore, trans-septal suturing in septoplasty was suggested as a safe procedure that can replace nasal packing, so that the postoperative complications especially post-operative pain, discomfort and prolonged hospital stay could be avoided. Also quality of life improvements measured through the NOSE score questionnaire were established.

To our knowledge, many of our collegues still avoid trans-septal suturing in septoplasty for fear of nasal bleeding, hematoma, adhesions and recurrence, and some of them have little knowledge about it. So, we had to change this concept and widen the basic knowledge about trans-septal suturing in septoplasty.

\section{Conclusion}

All parameters of comparison between trans-septal suturing and nasal packing in this study guided us to ensure that trans-septal suturing in septoplasty is a safe procedure and useful alternative to nasal packing with minor increase in operative time and nonsignificant increase in post-operative bleeding which was easily controlled.

\section{Acknowledgements}

None.

\section{Conflicts of interest}

Author declares there are no conflicts of interest.

\section{Funding}

None.

\section{References}

1. Gandomi B, Bayat A, Kazemei T. Outcomes of septoplasty in young adults: the Nasal Obstruction Septoplasty Effectiveness study. Am J Otolaryngol. 2010;31(3):189-192.

2. Erkhan G, Ergin NT, Bilezikçi B. Comparison of suture and nasal packing in rabbit noses. Laryngoscope. 2004;114(4):639-645.

3. Stewart MG, Smith TL, Weaver EM, et al. Outcomes after nasal septoplasty: results from the Nasal Obstruction Septoplasty Effectiveness (NOSE) study. Otolaryngol Head Neck Surg. 2004;130(3):283-290.

4. Rettinger G, Kirsche H. Complications in septoplasty. Facial Plast Surg. 2006;22(4):289-297.

5. Muhammad IA, Nabil-ur Rahman. Complications of the surgery for deviated nasal septum.JColl Physicians Surg Pak. 2003;13(10):565-568.

6. Ardehali MM, Bastaninejad S. Use of nasal packs and intranasal septal splints following septoplasty. Int J Oral Maxillofac Surg. 2009;38(10):1022-1024.

7. Dubin MR, Pletcher SD. Post-operative packing after septoplasty: is it necessary? Otolaryngol Clin North Am. 2009;42(2):279-285.

8. Dogan OT, Yildirim A, Epozturk K, et al. Another advantage of nasal septal suturing: pulmonary function unaffected. B-ENT. 2012;8(1):21-24.

9. Korkut AY, Teker AM, Eren SB, et al. A randomised prospective trial of trans-septal suturing using a novel device versus nasal packing for septoplasty. Rhinology. 2010;48(2):179-182.

10. Lemmens W, Lemkens P. Septal suturing following nasal septoplasty, a valid alternative for nasal packing? Acta Otorhinolaryngol Belg. 2001;55(3):215-221.

11. Cukurova I, Cetinkaya EA, Mercan GC, et al. Retrospective analysis of 697 septoplasty surgery cases: packing versus trans-septal suturing method. Acta Otorhinolaryngol Ital. 2012;32(2):111-114. 
12. Stewart MG, Witsell DL, Smith TL, et al. Development and validation of the Nasal Obstruction Symptom Evaluation (NOSE) scale. Otolaryngol Head Neck Surg. 2004;130(2):157-163.

13. Yanagisawa E, Latorre R. Choking spells following septorhinoplasty secondary to displaced nasal packing. Ear Nose Throat $J$. 1995;74(11):744-746.

14. Naghibzadeh B, Peyvandi AA, Naghibzadeh G. Does post septoplasty nasal packing reduce complications? Acta Med Iran. 2011;49(1):9-12.

15. Bernardo MT, Alves S, Lima NB, et al. Septoplasty with or without postoperative nasal packing? Prospective study. Braz J Otorhinolaryngol . 2013;79(4):471-474.

16. Ghimire A, Limbu TR, Bhandari R. Trans-septal suturing following septoplasty: an alternative for nasal packing. Nepal Med Coll J. 2012;14(3):165-168.

17. Cassisi NJ, Biller HF, Ogura JH. Changes in arterial oxygen tension and pulmonary mechanics with the use of posterior packing in epistaxis: a preliminar report. Laryngoscope. 1971;81(8):1261-1266.
18. Tassan VT, Wynne JW, Cassisi N, et al. The effect of nasal packing on sleep-disordered breathing and nocturnal oxygen desaturation. Laryngoscope. 1981;91(7):1163-1171.

19. Awan MS, Iqbal M. Nasal packing after septoplasty: A randomized comparison of packing versus no packing in 88 patients. Ear Nose Throat J. 2008;87(11):624-627.

20. Mane RS, Patil B, Mohite A. Comparison of septoplasty with and without nasal packing and review of literature. Indian J Otolaryngol Head Neck Surg. 2013;65(Supp1 2):406-408.

21. Weber R, Keerl R, Hochapfel F, et al. Packing in endonasal surgery. Am J Otolaryngol . 2001;22(5):306-320.

22. Basha SI, Gupta D, Kaluskar SK. Routine nasal packing following nasal surgery-is it necessary? Indian J Otolaryngol Head Neck Surg . 2005;57(1):69-71.

23. Bezerra TF, Stewart MG, Fornazieri MA, et al. Quality of life assessment septoplasty in patients with nasal obstruction. Braz J Otorhinolaryngol. 2012;78(3):57-62. 